\title{
ANALISA PBU-MIT GUNA PENENTUAN DELIVERABILITY DENGAN METODE KONVENSIONAL DAN LIT MENGGUNAKAN SOFTWARE SAPHIR DAN PERHITUNGAN MANUAL PADA SUMUR GAS $X$ LAPANGAN "Y"
}

\author{
Rizky B. Hauteas ${ }^{1)}$, Edi Purwaka ${ }^{2)}$ \\ ${ }^{1,2)}$ Prodi Teknik Perminyakan, Fakultas Teknik, Universitas Proklamasi 45 Yogyakarta \\ Coresponding author.email : rizkypetroleum13@gmail.com
}

\begin{abstract}
Abstrak
Penentuan nilai deliverabilitas dari sumur X Lapangan Y menjadi saah satu tahapan yang perlu dilakukan guna mengetahui kondisi sumur dan kemampuannya. Untuk mendapatkan nilai yang lebih mendekati dengan keadaan di lapangan, dilakukan perbandingan pada proses analisa yang ada, yaitu dengan membandingkan dua metode dalam analisa (dalam hal ini dibandingkan metode Konvensional dan LIT) maupun meode dalam proses perhitungannya (dalam hal ini menggunakan software maupun perhitungan secara manual). Hasil analisa dengan menggunakan software Saphir sebagai berikut $: \mathrm{k}=1810 \mathrm{mD}$, kompresibilitas $=$ $0.0687 \mathrm{bbl} / \mathrm{psi}$. Dengan well model : limited entry, reservoir model : dual porosity dan boundary model : infinite. Sedangkan hasil analisa secara analitikal sebagai berikut; $\mathrm{Pi}=573.5852$ psia, $\mathrm{m}=1137.017 \mathrm{psia}^{2} /$ cycle, $\mathrm{k}=906,33 \mathrm{mD}, \mathrm{s}=-3.77, \mathrm{PI}=3.932$ $\mathrm{mmscfd} / \mathrm{psia}^{2}, \mathrm{FE}=89,34 \%$ dan $\mathrm{ri}=45.04 \mathrm{ft}$. Hasil penentuan dan analisa deliverabilitas dengan metode konvensional mendapatkan harga AOF sebesar $29.4811 \mathrm{mmscf} / \mathrm{d}$ untuk perhitungan software dan $40.747 \mathrm{mmscfd}$ secara analitikal. Hasil penentuan dan analisa deliverabilitas dengan metode LIT mendapatkan harga AOF sebesar $23.9865 \mathrm{mmscf} / \mathrm{d}$ untuk perhitungan software dan 29.419 mmscfd secara analitikal. Dengan beberapa perimbangan dipilih nilai deliverability yang akurat pada sumur ini adalah sesuai metode LIT dengan harga AOF sebesar $23.9865 \mathrm{mmscf} / \mathrm{d}$.
\end{abstract}

Kata kunci : Deliverabilitas, Saphir, Konvensional, LIT

\section{Pendahuluan}

Seluruh kegiatan yang dilakukan oleh sebuah perusahaan khususnya dibidang Migas tentu saja memiliki orientasi untuk bisa mendapatkan hasil produksi maksimal dengan pertimbangan efisiensi dalam kegiatan eksplorasi maupun produksi. Disini jelas bahwa salah satu bagian yang menjadi dasar utama untuk mencapai orientasi itu, maka perlu diperhatikan kemampuan dari setiap sumur yang dimiliki, untuk berikutnya menjadi pertimbangan penting dalam menentukan target kedepannya. Salah satu kegiatan untuk mendapatkan nilai dari kemampuan sumur yang ada yaitu dengan melakukan uji sumur, hal inilah yang melatarbelakangi penulis untuk dapat menganalisa dengan baik kemampuan suatu sumur khususnya dalam hal ini yaitu sumur gas. Pelaksanaan uji sumur menjadi cara yang paling sering digunakan untuk mengetahui kondisi dari suatu sumur yang ada. Berbagai metode pengujian sumur ini terdiri dari beberapa metode seperti Analisa Pressure Build Up dan Pressure Draw Down. Salah satu metode yang sering digunakan yaitu Pressure Buid $U p$.

Pressure Build Up Testing (PBU) adalah suatu teknik pengujian transient tekanan yang paling dikenal dan banyak dilakukan. Pengujian ini dilakukan dengan cara memproduksikan sumur selama suatu selang waktu tertentu dengan laju aliran yang tetap (konstan), kemudian menutup sumur tersebut (dengan menutup kepala sumur) sehingga tekanan menjadi naik. Di sisi lain dengan dilakukannya test menggunakan analisa pressure build up ini maka bisa didapatkan nilai deliverability dari suatu sumur. Deliverability adalah kemampuan dari suatu reservoir gas untuk mengalirkan gas ke permukaan melalui media berpori yang dinyatakan dalam bentuk grafik hubungan tekanan dengan rate produksi ( $\left(\mathrm{Pr}^{2}-\right.$ $\left.\mathrm{Pwf}^{2}\right)$ vs qsc). Tujuan dari uji deliverability ini adalah untuk mengetahui penurunan tekanan dasar sumur $\left(\Delta \mathrm{P}^{2}\right)$ sehubungan dengan laju produksi konstan di kepala sumur $\left(\mathrm{q}_{\mathrm{sc}}\right)$ pada suatu sumur. Hal ini telah diterima secara luas bahwa $\log \left(\Delta \mathrm{P}^{2}\right)$ versus $\log \left(\mathrm{q}_{\mathrm{sc}}\right)$ memiliki hubungan yang mendekati linier. Terdapat tiga metode untuk uji deliverabilitas gas yang digunakan, yaitu : Back Pressure, Isochronal, dan Modified Isochronal.

Penggunaan metode-metode yang ada dalam kegiatan well test ini tentu saja memiliki hasil perhitungan yang berbeda-beda, hal ini tentu saja akan sangat berpengaruh pada analisa dan rencana terhadap lapangan yang ada berdasarkan data sumur tersebut. Dimana metode yang digunakan di ambil dari uji modified isochronal dengan metode konvensional dan laminar inertia turbulent dimana untuk tiap metode akan dihitung menggunakan software saphir dan dengan perhitungan manual.

Maksud dari penelitian ini yaitu menganalisa kondisisumur yang ada berdasarkan analisa PBU- 


\section{ANALISA PBU-MIT GUNA PENENTUAN DELIVERABILITY DENGAN METODE KONVENSIONAL DAN LIT MENGGUNAKAN SOFTWARE SAPHIR DAN PERHITUNGAN MANUAL PADA SUMUR GAS X LAPANGAN "Y"}

MIT dengan menggunakan software Saphir maupun secara analitik atau perhitungan manual. Dimana dalam prosesnya akan dilakukan perbandingan analisa deliverability dengan Metode Konvensional dan LIT pada perhitungan menggunakan software maupun manual.

Tujuan dari peneilitian ini yaitu untuk dapat menentukan kondisi dari sumur yang ada khususnya nilai deliverabilitas sumur tersebut dengan membandingkan metode Konvensional dan LIT (Laminer Inertia Turbulen) yang dihitungkan menggunakan software dan juga secara analitik/manual. Selanjutnya dapat dipilih nilai deliverabilitas yang sesuai atau mendekati keadaan sebenarnya di lapangan.

\section{Metodologi}

Dalam penelitian ini digunakan dua metode, yaitu analisa dan penentuan nilai deliverabilitas menggunakan metode konvensioanl dan menggunakan metode Laminer Inertia Turbulen. Hasil dari perhitungan dua metode ini akan dibandingkan dan dilakukan pemilihan nilai deliverabilitas yang lebih mendekati dengan kondisi di lapangan yang akan menjadi bahan pertimbangan untuk perencanaan tahapan selanjutnya unntuk sumur ini.

Tahapan dalam penelitian ini yaitu;

a. Studi Literatur, studi literatur difokuskan pada pencarian informasi dari buku-buku atau literatur untuk menunjang penelitian ini.

b. Pengumpulan Data, dilakukan pada saat kegiatan penelitian di perusahaan untuk mendapatkan data yang dibutuhkan dalam proses perhitungan dan analisa.

c. Perhitungan dan Analisa setelah mendapatakan data-data serta materi yang dapat menunjang dalam penelitian ini, maka selanjutnya dilakukan perhitungan dan analisa dari datadata tersebut.

d. Membandingkan nilai deliverabilitas yang didapat dari dua metode analisa dengan dua metode perhitungan yang ada untuk selanjutnya dipilih nilaideliverabilitas atau AOF (absolute open flow) yang sesuai/mendekatikeadaan di lapangan.

\section{Hasil dan Pembahasan}

Uji deliverabilitas merupakan suatu uji sumur yang umum digunakan untuk menentukan produktivitas sumur gas. Indikator produktivitas yang diperoleh adalah Absolute Open Flow Potential (AOFP), yang didefinisikan sebagai kemampuan suatu sumur gas untuk mem- produksikan gas ke permukaan dengan laju alir maksimum pada tekanan alir dasar sumur sebesar tekanan 1 atmosfer $( \pm 14.7$ psia $)$. Walaupun secara praktek hal ini tidak dapat diukur secara langsung tetapi dapat diperoleh dari uji Deliverability. Harga AOFP sering digunakan untuk menentukan laju alir maksimum yang diijinkan untuk sebuah sumur sehingga dapat memproduksi gas tanpa menyebabkan kerusakan formasi.

Uji sumur yang digunakan pada sumur " $\mathrm{X}$ " di lapangan "Y" adalah Modified Isochronal Test (MIT) dan Pressure Build Up (PBU). Sumur ini memulai program MIT dengan melakukan penutupan dan pengaliran dengan selang waktu kurang lebih 3 jam dan dengan harga laju alir $\left(\mathrm{q}_{\mathrm{sc}}\right)$ yang berbeda-beda yang prosesnya diulang sebanyak 4 kali.

Uji sumur pada penelitian ini, didapatkan data hasil PBU-MIT yang kemudian di analisa dengan menggunakan software Saphir maupun secara perhitungan manual.. Dimana dalam prosesnya mengggunakan software, data-data yang ada di input dan selanjutnya didapatkan output berupa bentukan log-log plot, semi-log plot, history plot dan juga AOF dengan metode konvensional maupun LIT. Sedangkan secara analitikal atau manual perhitungan dilakukan dengan menghitung variable-variabel yang diperlukan untuk mendapatkan niali AOF baik menggunakan metode konvensional maupun LIT.

\subsection{Analisa Hasil Plot Berdasarkan Output Pada Software Saphir}

Hasil plot-plot yang sudah ada, terdapat beberapa plot yang dapat dibahas lebih lanjut sebagai berikut:

Gambar 1 merupakan hasil interpretasi untuk well model, reservoir model dan juga boundary modelnya. Dalam proses pemilihannya untuk pemilihan well model di dasarkan pada kondisi lubang sumur yang ada, dimana pada pelaksanaan kegiatan perforasinya hanya dilakukan pada beberapa titik interval saja dan tidak sepanjang layer yang ada, sehingga aliran yang masuk kedalam lubang sumur menjadi terbatas. Karena iu pemilihan well model untuk sumur ini yaitu limited entry.

Selanjutnya pada pemilihan reservoir model, terlebih dahulu kita melakukan analisa sebaiknya kita perlu mengetahui informasi tentang struktur atau data geologi dari reservoir yang ada, sehingga hasil analisa yang ada bisa tepat sesuai dengan kondisi sebenarnya. Untuk sumur X ini, informasi yang didapat bahwa reservoir yang ada terbentuk oleh batuan karbonat. Untuk batuan jenis ini biasanya tidak hanya memiliki satu jenis porositas 
saja, bukan hanya porositas yang homogeny tapi juga memiliki porositas tambahan seperti akibat adanya rekahan-rekahan lain yang terbentuk. Jadi porositas yang ada ini terdiri dari dua porositas yaitu matriks (memiliki nilai strotavitas yang tinggi dan permeabilitas rendah) dan juga fissures (memiliki permeabilitas tinggi dan strotavitas yang rendah). Pada gambar di atas terlihat bahwa garis model reservoir yang ada mengalami penurunan yang cukup jauh dari garis nilai permeabilitas yang ada, ini juga menjadi bahan pertimbangan sendiri mengapa dipilih model dual porosity.

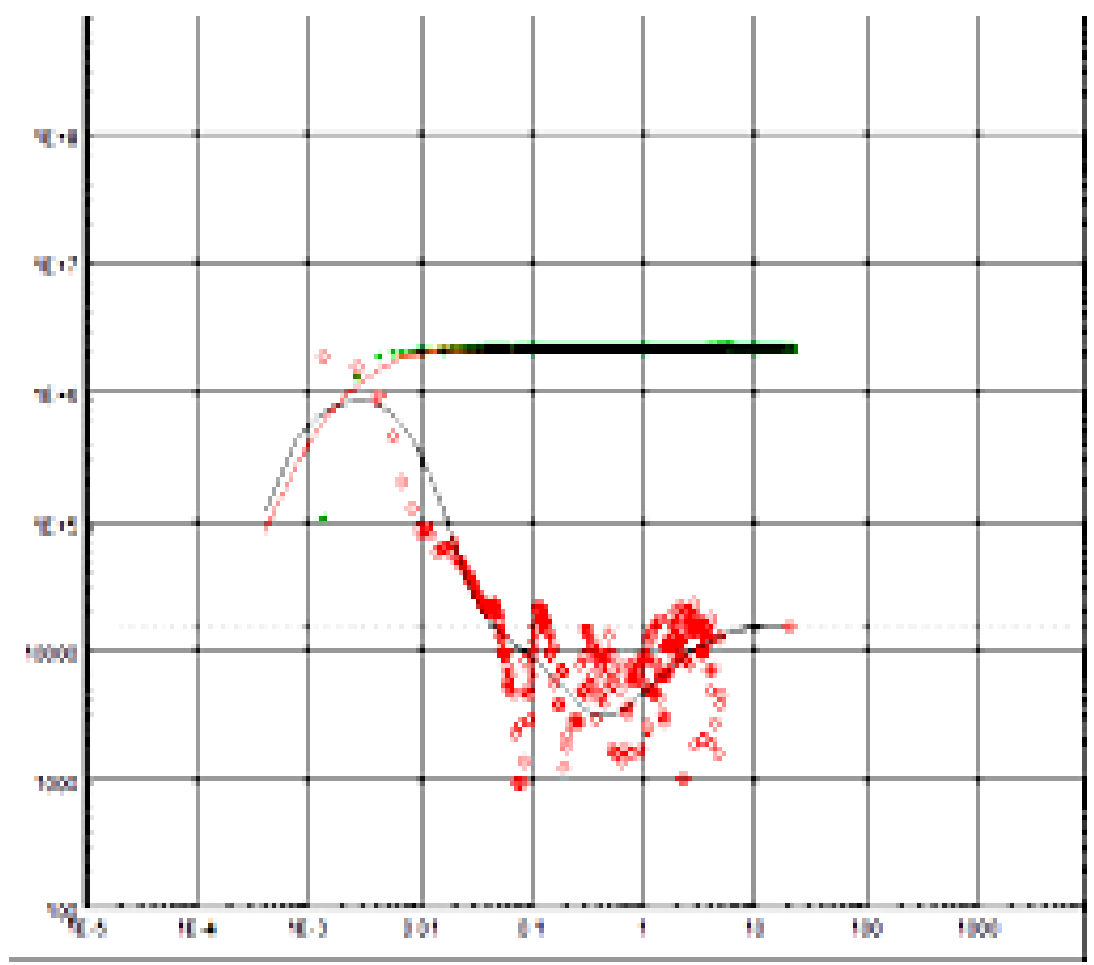

Gambar 1. Log-Log Plot

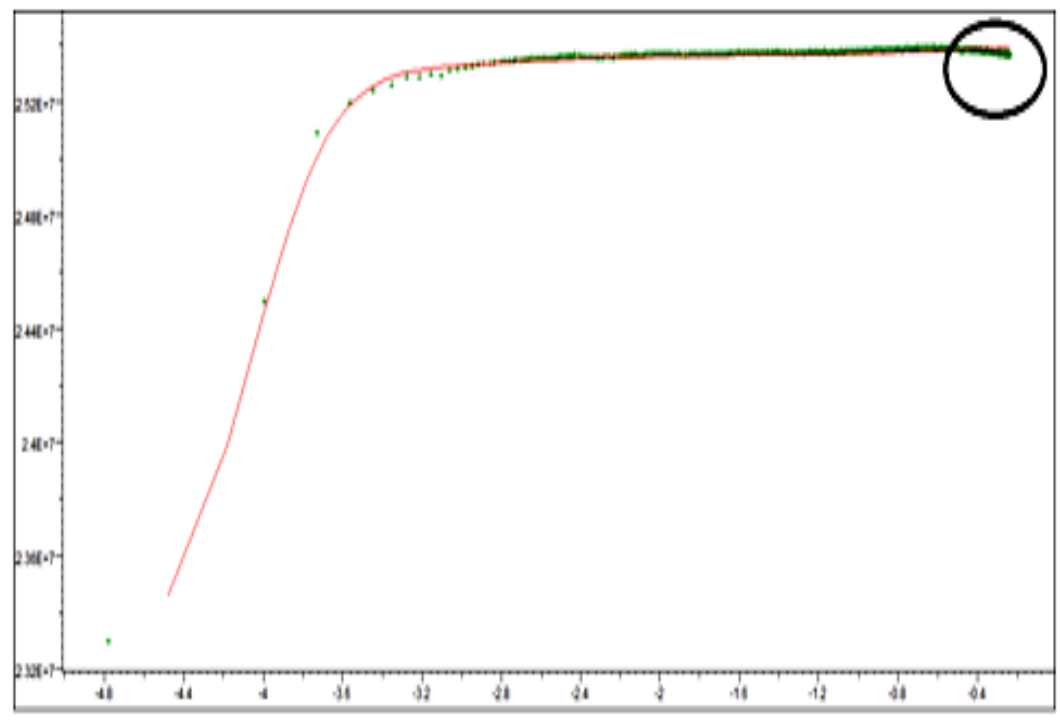

Gambar 2. Semi-log Plot

Pemilihan boundary model pada kegiatan analisa PBU-MIT kali ini sebenarnya berdasarkan data yang ada belum dapat digunakan dijadikan acuan. Karena dalam prosesnya waktu yang digunakan memang kurang panjang yaitu hanya 24 jam, dengan pertimbangan lain bahwa sumur ini 


\section{ANALISA PBU-MIT GUNA PENENTUAN DELIVERABILITY DENGAN METODE KONVENSIONAL DAN LIT MENGGUNAKAN SOFTWARE SAPHIR DAN PERHITUNGAN MANUAL PADA SUMUR GAS X LAPANGAN "Y"}

pun berada di antara sumur-sumur lain yang tentu saja dapat mengintervensi tekanan, sehingga mempengaruhi bentukan kurva yang ada.

Berdasarkan Gambar 2, terlihat bahwa terdapat penurunan tekanan. Hal ini menunjukan bahwa tekanan yang ada telah dintervensi oleh sumur lain, dimana apabila sumur yang satu dibuka dan yang lainnya ditutup maka penentuan akan batasan ini menjadi tidak layak. Di sisi lain pada program pelaksanaan kegiatan MIT untuk sumur ini memang tidak bertujuan untuk mengetahui boundary model yang ada, jadi pemilihan boundary model pada sumur ini dianggap infinite mengingat kondisi reservoir dan lapangan yang ada.

Tabel 1. Hasil Perhitungan Karakteristik Sumur Menggunakan Software

\begin{tabular}{|c|c|c|}
\hline PARAMETER & NILAI & SATUAN \\
\hline C & 0.0687 & Bbl/psi \\
\hline Skin & 43.1 & - \\
\hline Delta P Skin & 16.2703 & Psi \\
\hline Pseudo Skin & 15.4 & - \\
\hline Delta P P.skin & 5.52061 & Psi \\
\hline Hw & 26.25 & Ft \\
\hline Zw & 52.49 & Ft \\
\hline H & 91.9 & Ft \\
\hline Pi & 1380 & Psia \\
\hline k.h & $1.67 \mathrm{E}+5$ & $\mathrm{md} . \mathrm{ft}$ \\
\hline $\mathrm{K}$ & 1810 & $\mathrm{mD}$ \\
\hline
\end{tabular}

Nilai skin yang ada yaitu 43.1 menunjukan bahwa kondisi sumur yang ada mengalami kerusakan formasi sebagai akibat dari pengaruh faktor geometri maupun kegiatan pemboran dan produksi yang dilakukan. Dalam hal ini skin yang ada juga dipengaruhi oleh titik perforasi yang ada, kondisi lubang perforasai yang hanya pada beberpa titik saja mempengaruhi banyaknya fluida yang dapat mengalir ke dalam lubang sumur.

Nilai permeabilitas yang ada termasuk dalam kondisi yang baik, dengan $1810 \mathrm{mD}$ tentunya sangat mempengaruhi laju alir gas dari formasi ke dalam lubang sumur. Sedangkan untuk nilai Zw dan Hw menunjukan letak/ jarak interval pada titik perforasi dan juga pada jarak titik tengah perforasai dengan titik dasar lubang sumur yang ada. Untuk nilai $H$ sendiri menunjukan tebalnya lapisan produktif yaitu sekitar $91.9 \mathrm{ft}$.

\subsection{Analisa Hasil Perhitungan PBU-MIT Berdasarkan Perhitungan Manual}

Dalam penelitian ini, perhitungan pada analisa PBU dilakukan dengan dengan menggunakan Metode Horner. Data tekanan dan waktu yang ada digunakan sebagai acuan untuk mendapatkan bentukan dua buah grafik yaitu grafik log-log plot antara $\Delta \mathrm{P}$ vs $\Delta \mathrm{t}$ dan grafik semilog plot antara $\mathrm{P}_{\mathrm{ws}}^{2}$ vs $\left(\frac{t p+\Delta t}{\Delta t}\right)$. Perhitungan dan analisis pada Metode Horner untuk PBU akan diperoleh beberapa parameter nilai dari : $\mathrm{P}^{*}\left(\bar{P}_{\mathrm{R}}\right)$, slope (m), k, P1jam, skin, $\Delta$ pskin, dan $r_{i}$.

Sesuai dengan grafik log-log plot antara $\Delta \mathrm{P}$ vs $\Delta \mathrm{t}$ maupun grafik semilog plot antara $\mathrm{P}_{\mathrm{ws}}{ }^{2}$ vs $\left(\frac{t p+\Delta t}{\Delta t}\right)$, didapat nilai $\mathrm{P}^{*}=573.585$ psia, nilai slope $(\mathrm{m})=1137.017 \mathrm{psia}^{2} /$ cycle, nilai P1jam $=$ 572.293 psia, yang selanjutnya nilai-nilai yang didapat dipakai untuk menentukan nilai permeabilitas, skin, $\Delta$ Pskin maupun indeks produktivitas, flow efficiency dan radius investigasi. Keseluruhan hasil perhitungan yang ada dapat dilihat pada tabel 2 .

Pada bagian MIT dilakukan perhitungan dan analisa dengan Metode Konvensional (RawlinSchelhard), dan Metode Laminar Inertial Turbulent (LIT). Untuk perhitungan dan analisa deliverability berdasarkan MIT menggunakan metode konvensional akan diperoleh parameter-parameter seperti C dan n. Sedangkan berdasarkan metode LIT akan diperoleh a dan b. Parameter-parameter yang ada akan digunakan untuk menentukan besarnya nilai AOF yang selanjutnya digunakan untuk membuat Kurva Deliverability. 
Tabel 2. Hasil Analisa PBU Secara Analitikal

\begin{tabular}{|c|c|c|}
\hline Parameter & Nilai & Satuan \\
\hline $\mathrm{P}^{*}(\mathrm{Pi})$ & 573.5852 & Psia \\
\hline $\mathrm{M}$ & 1137.017 & $\mathrm{Psia}^{2} / \mathrm{cycle}$ \\
\hline $\mathrm{P} 1 \mathrm{jam}$ & 572.293 & $\mathrm{Psia}$ \\
\hline $\mathrm{K}$ & 906.33 & $\mathrm{mD}$ \\
\hline $\mathrm{S}$ & -3.37 & \\
\hline$\Delta$ Pskin & 61.096 & Psia \\
\hline $\mathrm{PI}$ & 3.932 & $\mathrm{Mmscfd} / \mathrm{psia}^{2}$ \\
\hline $\mathrm{FE}$ & 89.34 & $\%$ \\
\hline $\mathrm{Ri}$ & 45.04 & $\mathrm{Ft}$ \\
\hline
\end{tabular}

Berdasarkan perhitungan yang dilakukan didapat hasil analisa deliverabilitas dengan metode konvensional yaitu sebesar 40.447 mmscfd dengan parameter $\mathrm{n}=0.759$ dan $\mathrm{c}=0.002614$ $\mathrm{mmscfd} / \mathrm{psia}^{2}$. Sedangkan analisa deliverabilitas dengan metode Laminer Inertia Turbulent (LIT) didapat AOF sebesar 29.419 MMSCFD.

\subsection{Perbandingan Deliverabilitas Sumur Berdasarkan Metode Konvensional Dan Metode LIT Menggunakan Software dan Perhitungan Manual}

Berdasarkan hasil perhitungan nilai $\mathrm{AOF}$ untuk tiap metode yang ada, nilai-nilai AOF yang ada memiliki perbedaan yang cukup besar, baik itu antar metode dalam satu jenis perhitungan maupun antar metode beda jenis perhitungan.

\section{a. Perbandingan Metode Konvensional dan LIT}

Secara umum perbedaan pada nilai AOF yang ada pada perhitungan dengan metode konvensional maupun LIT baik menggunakan software maupun manual memiliki perbedaaan yang cukup besar. Pertimbangan yang dipakai pada pemilihan nilai AOF yang ada tentunya kembali ke parameter yang digunakan dalam perhitungan $\mathrm{AOF}$ ini sesuai dengan metode masing-masing. Dalam prosesnya, perbedaan perhitungan antara kedua metode ini yaitu pada ada tidaknya pemakaian parameter pseudo pressure/ faktor kompresibilitas gas. Dimana untuk kedua metode ini, penggunaan pertimbangan koreksi pada faktor kompresibilitas gas atau nilai $\mathrm{Z}$ digunakan pada metode LIT.

Metode Analisis LIT analisa dianggap lebih teliti karena menggunakan pseudo-pressure dan dapat digunakan pada semua kisaran tekanan reservoir, bila dibandingkan dengan analisa pendekatan tekanan $(\mathrm{P})$ atau analisa pendekatan tekanan kuadrat $\left(\mathrm{P}^{2}\right)$. Metode ini dapat digunakan pada kondisi real gas dan hanya membutuhkan satu data uji aliran stabil. b. Perbandingan Jenis Perhitungan dengan Software dan Manual

Perbedaan antara dua jenis perhitungan ini cukup besar, baik itu hasil AOF pada metode konvensional maupun pada metode LIT. Secara spesifik terdapat beberapa faktor yang membuat selisih diantaranya cukup besar, yaitu:

- Perbedaaan data inputan nilai laju aliran dan tekanan.

- Perbedaan metode analisa antara Horner pada perhitungan manual dan derivatif pada software

- Perbedaan penggunaan nilai pseudo pressure.

Sesuai dengan faktor-faktor pembeda di atas, dalam prosesnya perhitungan/analisa yang dilakukan secara manual maupun dengan menggunakan software merujuk pada jenis perhitungan mana yang lebih mendekat dengan kondisi di lapangan khususnya pada sumur yang ada. Dalam hal ini proses analisa menggunakan software dipilih sebagai jenis perhitungan yang lebih mendekati kondisi di lapangan. Secara khusus ini ditemukan perbedaannya pada saat input data tekanan dan laju alir, pada perhitungan secara manual data yang ada sesuai hasil program uji sumur langsung digunakan sebagai acuan untuk perhitungan parameter-parameter yang ada. Sedangkan pada saat menggunakan software data inputan tekanan dan laju alir masih perlu dilakukan matching agar sesuai dengan kondisi di lapangan. Hal ini tentu saja berdampak lebih pada saat penentuan nilai deliverability dari sumur yang ada, dimana terdapat perbedaan pada saat inputan manual dengan inputan pada software.

Berdasarkan pertimbangan-pertimbangan yang dijelaskan di atas, maka nilai deliverability yang dianggap sesuai dan mendekati dengan kondisi di lapangan yaitu nilai AOF berdasarkan metode LIT yahng dihitung menggunakan software saphir yaitu sebesar 23.9865 MMSCFD.

Berikut ini merupakan tabel tabulasi perbandingan AOF menggunakan Software maupun secara perhitungan manual. 


\section{ANALISA PBU-MIT GUNA PENENTUAN DELIVERABILITY DENGAN METODE KONVENSIONAL DAN LIT MENGGUNAKAN SOFTWARE SAPHIR DAN PERHITUNGAN MANUAL PADA SUMUR GAS X LAPANGAN "Y"}

Tabel 3. Perbandingan Hasil Analisa Deliverabilitas Metode Konvensional dan Metode LIT Sumur "X"

\begin{tabular}{|c|c|c|c|}
\hline \multicolumn{4}{|c|}{ METODE PERHITUNGAN } \\
\hline \multicolumn{2}{|c|}{ KONVENSIONAL } & \multicolumn{2}{c|}{ LIT } \\
\hline $\begin{array}{c}\text { SOFTWARE } \\
\text { (MMSCFD) }\end{array}$ & $\begin{array}{c}\text { MANUAL } \\
\text { (MMSCFD) }\end{array}$ & $\begin{array}{c}\text { SOFTWARE } \\
\text { (MMSCFD) }\end{array}$ & $\begin{array}{c}\text { MANUAL } \\
\text { (MMSCFD) }\end{array}$ \\
\hline 29.481 & $\mathbf{4 0 . 4 4 7}$ & $\mathbf{2 3 . 9 8 6}$ & $\mathbf{2 9 . 4 1 9}$ \\
\hline
\end{tabular}

\section{Kesimpulan}

Berdasarkan hasil analisa dan pembahasan yang ada, dapat diambil beberapa kesimpulan sebagai berikut:

1. Hasil analisa dengan menggunakan software Saphir sebagai berikut : $\mathrm{k}=1810 \mathrm{mD}$, kompresibilitas $=0.0687 \mathrm{bbl} / \mathrm{psi}$. Dengan well model : limited entry, reservoir model : dual porosity dan boundary model : infinite.

2. Hasil analisa secara analitikal sebagai berikut; $\mathrm{Pi}=573.5852 \mathrm{psia}, \mathrm{m}=1137.017 \mathrm{psia}^{2} / \mathrm{cycle}$, $\mathrm{k}=906,33 \mathrm{mD}, \mathrm{s}=-3.77, \mathrm{PI}=3.932$ $\mathrm{mmscfd} / \mathrm{psia}^{2}, \mathrm{FE}=89,34 \%$ dan $\mathrm{ri}=45.04 \mathrm{ft}$.

3. Hasil penentuan dan analisa deliverabilitas dengan metode konvensional mendapatkan harga AOF sebesar $29.4811 \mathrm{mmscf} / \mathrm{d}$ untuk perhitungan software dan $40.747 \mathrm{mmscfd}$ secara analitikal.

4. Hasil penentuan dan analisa deliverabilitas dengan metode LIT mendapatkan harga AOF sebesar $23.9865 \mathrm{mmscf} / \mathrm{d}$ untuk perhitungan software dan 29.419 mmscfd secara analitikal.

5. Nilai deliverability yang akurat pada sumur ini adalah sesuai metode LIT dengan harga AOF sebesar $23.9865 \mathrm{mmscf} / \mathrm{d}$, dengan beberapa pertimbangan yaitu ;

- Perbedaaan data inputan nilai laju aliran dan tekanan.

- Perbedaan metode analisa antara Horner pada perhitungan manual dan derivatif pada software.

- Perbedaan penggunaan nilai pseudo pressure.

Dimana pertimbangan akan perolehan nilai yang didapat lebih sesuai dengan kondisi di lapangan.

\section{Daftar Pustaka}

Abdassah, Doddy, "Teknik Gas Bumi", Jurusan Teknik Perminyakan Institut Teknologi Bandung.
Amyx, James W, Bass Daniel M., Robert L. Whiting, "Petroleum Reservoir Engineering Physical Properties", Mc.Graw Hill Book Company New York, USA - Toronto Canada - London, England, 1960.

Bourdet, Dominique.,"Well Test Analysis: The Use of Advanced Interpretation Models", Elsevier Science B. V., Amsterdam, Netherland, 2002.

Brown, Kermit E., "The Technology of Artificial Lift Method vol.4, Production Optimation of Oil and Gas Well by Nodal System Analysis", Penn well PublishingCompany, Tulsa, Oklahoma.

Lee, John., "Well Testing", Society of Petroleum Engineering of AIME, New York, Dallas, 1982.

Matthew, C. S, Russell, D. G., "Pressure Buildup and Flow Test in Wells", Henry L. Doherty Memorial Fund of AIME, Society of Petroleum Engineeers, Richardson, TX U.S.A.

Dodson, C.R., Standing,M.B., "Pressure-VolumeTemperature and Solubility Rlation for Natural Gas-Water Mixture, Drilling and Production", Prac., API, 1994.

".............. Saphir Version 3.20 Manual Book", Kappa Engineering.

“..................Dynamic Data Analysis Book", Kappa Engineering.

Economides, M.J., Noltek, K.G., "Reservoir Stimulation", $2^{\text {nd }}$ Edition, Prentice Hall, Englewood Cliffs, New Jersey 07632, 1989. ..Data Lapangan PT. Pertamina EP Asset 2 pada Sumur "X", Lapangan "Y". 